\title{
Supporting navigator's decisions by visualizing ship collision risk
}

\author{
Rafał Szłapczyński, Ph. D. \\ Gdańsk University of Technology \\ Roman Śmierzchalski, Assoc. Prof. \\ Gdynia Maritime Academy
}

\begin{abstract}
The paper introduces a visualization method that enables the navigator to estimate an encounter situation and choose collision avoidance manoeuvre, if necessary. It is based on the Collision Threat Parameters Area method and offers new features: fuzzy sectors of forbidden speed and course values, the possibility to use any given ship domain and a new formula of collision risk assessment. All these elements result in a method, which enables the navigator to differentiate between varying levels of risk and to point out the direct threats. The method is fast enough to be applied in the real-time decision support system.
\end{abstract}

Key words: ARPA display, collision avoidance manoeuvres, collision risk, navigation

\section{INTRODUCTION}

Traditional displays used in collision-avoidance systems were based on the relative Cartesian coordinate system, with the own ship in the centre of it and $\mathrm{X}$ and $\mathrm{Y}$ coordinates denoting the relative positions of all other objects including ships - here called targets. Their functionality was limited to showing all targets within a certain range and indicating the targets that were considered to be dangerous on the basis of computations performed by the system. Some of them additionally visualized Predicted Areas of Danger (PAD) and the resulting necessary course alterations [9]. What these displays failed to visualize was the nature of collision risk: the colliding combinations of courses and speeds of the own ship and the dangerous targets. Visualizing these forbidden combinations of course and speed (instead of course only) has been introduced by Lenart as a part of Collision Threat Parameters Area (CTPA) method [1].

Based on CTPA the graphical method determining necessary manoeuvre has been introduced in $[6,7,8]$. However, the display according to Lenart and the derived method naturally assume using a pre-defined safe distance $\mathrm{D}_{\mathrm{S}}$ as a main safety parameter and consequently DCPA (Distance to the Closest Point of Approach) as a collision risk measure. Therefore they cannot be used for precise visualization of the necessary manoeuvres when domains other then circle-shaped are assumed. Also, in cases of large values of safe distance parameter $D_{S}$ and multi ship encounters it might be impossible to find one combination of course and speed that avoids collisions with all targets. In such cases the targets should be ranked according to their risk factor values and a sequence of collision avoidance manoeuvres should be applied.
In [5] the following ideas have been combined: double coordinate system used in CTPA, a fuzzy ship domain [3] and approach factor $\mathrm{f}_{\text {min }}$ - a new measure of collision risk derived from the concept of a ship domain [4]. Approach factor $\mathrm{f}_{\text {min }}$ has been defined as the scale factor of the largest domain-shaped area that is predicted to remain free of other ships throughout the whole encounter situation. The result presented in [5] has been a new visualization method called Fuzzy Collision Threat Parameters Area (FCTPA). It has been based on Collision Threat Parameters Areas method and has extended it so as to handle any given domain, including fuzzy domains.

In this paper the FCTPA method is further modified and a generalized version of a formula for collision risk $[6,7,8]$ is applied. The original formula presented in $[6,7,8]$ took into account both DCPA (Distance at the Closest Point of Approach), and TCPA (Time remaining to the Closest Point of Approach), thus emphasizing the direct threat of the nearest close encounters. It also reflected the non-linearity of the collision risk (as a function of distance and time) near the critical values of minimum safe distance $\mathrm{D}_{\mathrm{S}}$ and minimum time for manoeuvring $T_{S}$. The generalized version of the formula replaces DCPA and TCPA with $f_{\min }$ and $t_{\text {min }}$ - the approach factor value and the time remaining to reaching this value. The modified version of the FCTPA visualization method applying the new formula for collision risk factor is called Two-Parameter Collision Threat Area (TPCTA).

The rest of the paper is organized as follows. Section 2 briefly describes the CTPA method. In Section 3 the formulas for collision risk assessment are provided and in Section 4 the new TPCTA method is presented. An exemplary scenario of using this method is given in Section 5. Finally Section 6 is a summary of the paper. 


\section{COLLISION THREAT PARAMETERS AREA (CTPA)}

In [1] a collision threat is defined as a target ship for which the following condition holds:

$$
\mathrm{DCPA}<\mathrm{D}_{\mathrm{S}}
$$

The method uses a double Cartesian coordinate system where the horizontal axis represents both the $\mathrm{X}$ coordinate of position and $\mathrm{V}_{\mathrm{X}}$ coordinate of speed and the vertical axis represents both the $\mathrm{Y}$ coordinate of position and $\mathrm{V}_{\mathrm{Y}}$ coordinate of speed. The relation between the position and speed coordinates is as follows:

$$
\begin{aligned}
& \mathrm{x}=\mathrm{V}_{\mathrm{x}} * \tau \\
& \mathrm{x}=\mathrm{V}_{\mathrm{y}} * \tau
\end{aligned}
$$

where:

$\tau$ - fixed time value, for example 12 minutes.

The Collision Threat Parameters Area for a single target ship is defined as an area in the abovementioned system of coordinates that fulfils the following conditions:

$\star$ placing the tip of the own speed vector $\mathrm{V}$ within this area would result in violating the safe distance $\mathrm{D}_{\mathrm{S}}$ between the ships

$\star$ placing the tip of the own speed vector $\mathrm{V}$ outside this area would result in keeping the safe distance $\mathrm{D}_{\mathrm{S}}$ between the ships.

The Collision Threat Parameters Area for a group of target ships is defined as a superposition of the Collision Threat Parameters Areas obtained for each of the targets separately. Graphical superposition has been presented in $[6,7,8]$. The formula for the two straight lines determining the boundaries of the CTPA for a given single target is as follows:

$$
\begin{aligned}
& \mathrm{y}=\mathrm{a}_{1} \mathrm{x}-\mathrm{b}_{1} \tau \\
& \mathrm{y}=\mathrm{a}_{2} \mathrm{x}-\mathrm{b}_{2} \tau
\end{aligned}
$$

where the coefficients are given by the formulas:

$$
\begin{gathered}
a_{1}=\frac{x_{r} y_{r}+D_{S} \sqrt{x_{r}^{2}+y_{r}^{2}-D_{S}^{2}}}{x_{r}{ }^{2}-D_{S}{ }^{2}} \\
b_{1}=\frac{x_{r} y_{r}-D_{S} \sqrt{x_{r}{ }^{2}+y_{r}{ }^{2}-D_{S}{ }^{2}}-V_{t y}}{x_{r}{ }^{2}-D_{S}{ }^{2}} \\
b_{2}=a_{2} V_{t x}-V_{t y}
\end{gathered}
$$

where:

$\mathrm{x}_{\mathrm{r}}, \mathrm{y}_{\mathrm{r}}$ - coordinates of the relative position of the target ship

$\mathrm{V}_{\mathrm{tx}}, \mathrm{V}_{\mathrm{ty}}-$ coordinates of the true speed of the target ship.

In practice, CTPA is only this part of the determined area, where the condition TCPA $>0$ holds, since only future collision threats are of interest. Also, in case of a multiple target encounter, the manoeuvres for which the safe distance $D_{S}$ would be violated after a time longer than the critical time (DCPA $<\mathrm{D}_{\mathrm{S}}$, TCPA $>\mathrm{T}_{\mathrm{C}}$ ) may be allowed, if there is no possibility of avoiding all targets with just one manoeuvre. This means that the tip of the own speed vector may be conditionally placed within this part of the CTPA, for which TCPA $>T_{C}$. When applied to the graphical display, the CTPA method enables the operator to choose manually a safe own speed vector in a very easy way - it is enough to choose a point outside the CTPA and read its speed coordinates. The method is summarized by Fig. 1 and Fig. 2.

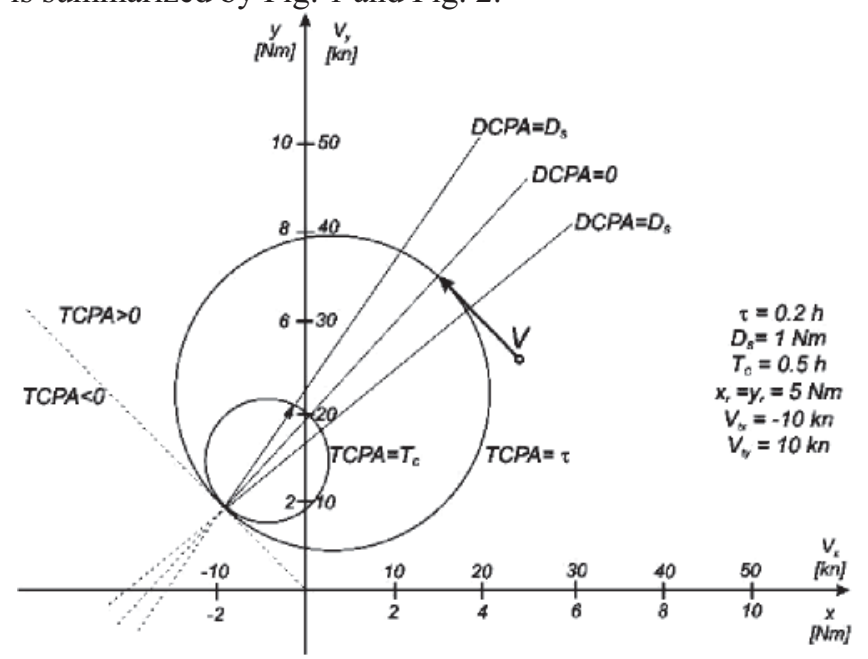

Fig. 1. Collision Threat Parameters Area by Lenart

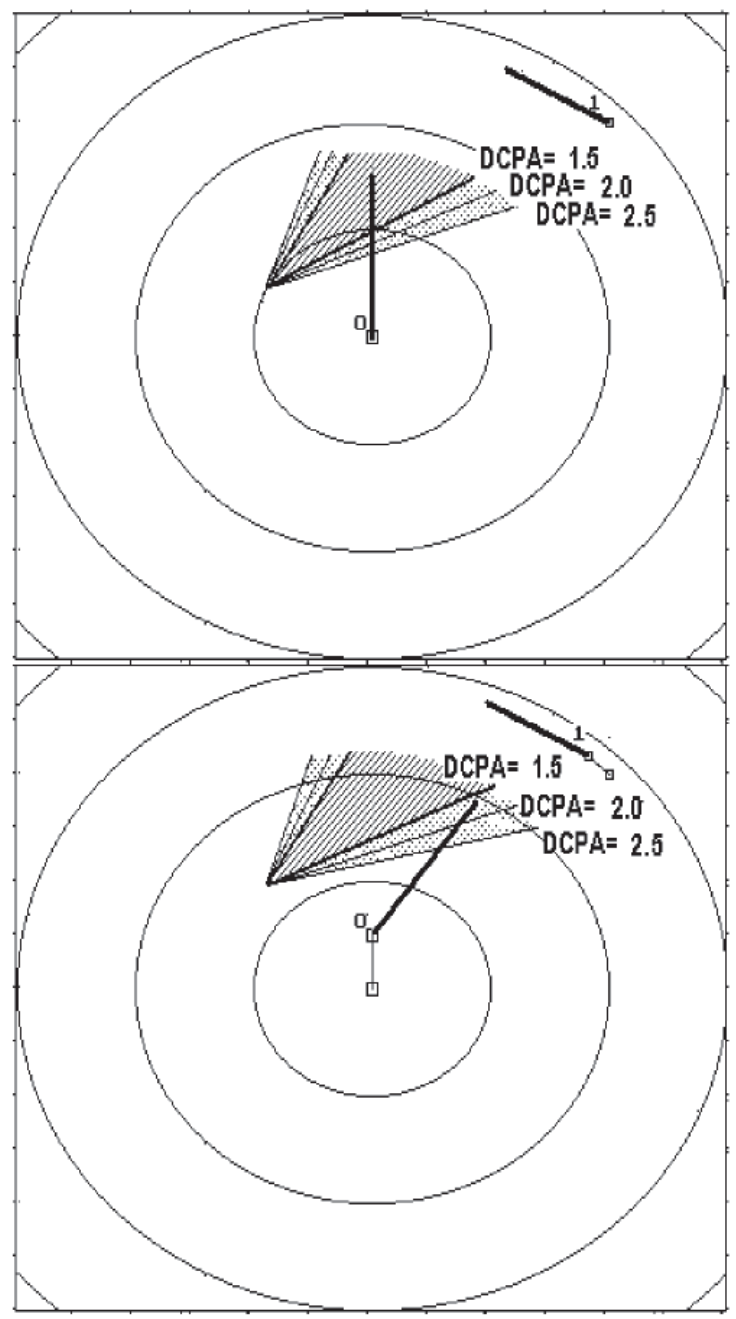

Fig. 2. Graphical interpretation of an encounter of two ships: before a collision avoidance manoeuvre (up side) and after the manoeuvre (down side)

The line of DCPA $=0$ represents a perfect crash. If the tip of the own speed vector is placed above this line, it means that the own ship will pass ahead of a target, if below this line 
- astern of a target. Fig. 2 presents a graphical interpretation of an encounter of two ships: before and after a collision avoidance manoeuvre. The own ship is moving with the speed of 15 knots and course 0 degrees and a target ship with the speed of 10 knots and course 300 degrees. The tip of the own speed vector is placed above the line for $\mathrm{DCPA}=1.5 \mathrm{n} . \mathrm{m}$. Therefore a collision avoidance manoeuvre is taken and the new own course is set to 35 degrees. New positions of ships are visualised after the time $t$ representing the physical realization of this manoeuvre.

\section{POINTING OUT THE DIRECT THREATS IN MULTI SHIP ENCOUNTER SITUATIONS}

To determine which targets constitute direct threat and have to be avoided first, it is necessary to monitor their motion parameters and to assign to them values of collision risk factor according to a given formula. Such formula for collision risk factor has been proposed by Lisowski [2] and it is as follows.

$r=\left[a_{1}\left(\frac{D C P A}{D_{S}}\right)^{2}+a_{2}\left(\frac{T C P A}{T_{S}}\right)^{2}+a_{3}\left(\frac{D}{D_{S}}\right)^{2}\right]^{-\frac{1}{2}}$

where:

$\mathrm{r} \quad-$ collision risk factor

D - current distance between the own ship and the target ship

$\mathrm{D}_{\mathrm{S}} \quad-$ safe distance of approach (a radius of the circleshaped domain),

$\mathrm{T}_{\mathrm{S}} \quad-$ a safe time necessary to plan and perform a collision avoidance manoeuvre,

$a_{1}, a_{2}, a_{3}-$ weight coefficients, dependent on the state of visibility at sea, dynamic length and dynamic beam of the ship and a kind of water region.

The advantage of this formula is that it can be applied to any target. However, the formula will indicate a considerable risk for $\mathrm{DCPA}=\mathrm{D}_{\mathrm{s}}$ and TCPA $=0$, that is, when the ships pass each other at a safe distance and there is no risk involved any more.

It must be emphasized that the most important elements affecting collision risk are: vector of relative speed (the superposition of the own speed and the speed of a target) and the lack of change of the target's bearing. These elements have been taken into account in $[6,7,8]$. Additionally it has been proposed there to limit the considered range of DCPA and TCPA values to the real collision risk area.(| DCPA $\mid \in\left(0, \mathrm{D}_{\mathrm{s}}\right)$ and TCPA $\in\left(0, \mathrm{nT}_{\mathrm{s}}\right)$, as given by conditions of formula (7). CTPA method by Lenart has been used, with the following modification applied: the function (7) has been introduced, which is strongly non-linear around the critical values of DCPA and TCPA. Thus modified collision risk factor $r$ as a function of DCPA and TCPA is also shown in Fig. 3.

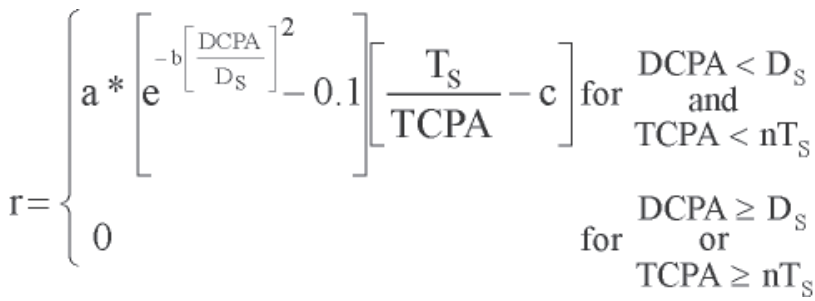

where:

$1 \geq \mathrm{r} \geq 0 \mathrm{n}>1$

$\mathrm{a}, \mathrm{b}, \mathrm{c}-$ values determined in the course of simulation: $\mathrm{a}=1.11, \mathrm{~b}=1.52, \mathrm{c}=0.33$.

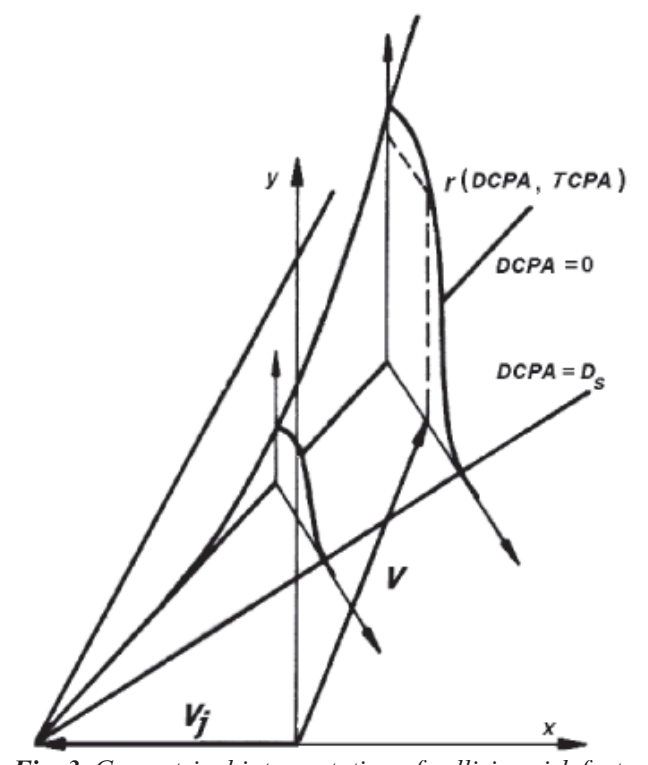

Fig. 3. Geometrical interpretation of collision risk factor

In the formula above the DCPA/ $\mathrm{D}_{\mathrm{S}}$ quotient is used, which is exactly the approach factor value $f_{\min }$ [4] for a circle-shaped domain. In case of using a ship domain model other than that, this quotient can be replaced with the $\mathrm{f}_{\text {min }}$ value obtained for this model. Similarly TCPA might be replaced with the time remaining to reaching $f_{\min }$ value. The generalization of the formula (7), which would hold true for any given ship domain would thus be:

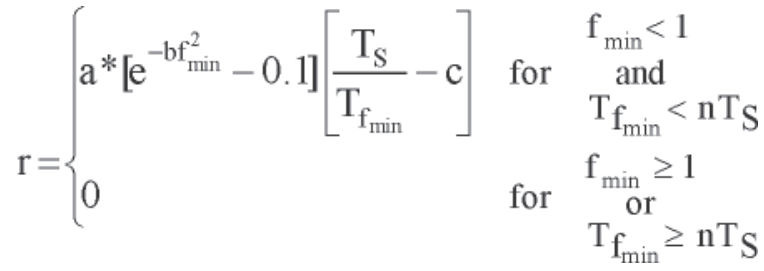

Using the formula (8), we can rank the targets according to the decreasing values of the risk factor $r$.

\section{DIRECT COLLISION THREAT PARAMETERS AREA (DCTPA).}

In this section a visualization tool that has been designed by the authors - Direct Collision Threat Parameters Area (DCTPA) is presented. It is based on the same concept of the forbidden area in the double Cartesian coordinate system, but instead of determining the area analytically for a fixed $D_{S}$ value, it is determined numerically for a given ship domain. It works as follows. For every combination of the own course and speed the resulting $f_{\min }$ value is computed (the algorithms used to compute the $f_{\min }$ value for given courses, positions and speeds of the own ship and target ships have been presented in detail in [4]). Then for each combination of the own course and speed the risk factor for each target is computed according to formula (8) and the minimal of those risk factor values is assigned to the current combination of course and speed.

Depending on the obtained value, a point in the double Cartesian coordinate system representing a particular combination of the own speed and course is assigned a colour in the following way:

for $0.75<\mathrm{r} \leq 1$ (critical collision risk): black

? for $0<\mathrm{r} \leq 0.75$ ( ignificant collision risk): gradually changing dark grey

? for $0<\mathrm{r} \leq 0.5$ (significant collision risk): gradually changing light grey

for $\mathrm{r}=0$ (safe passing): white

The proposed visualisation tool is shown in Fig. 4 


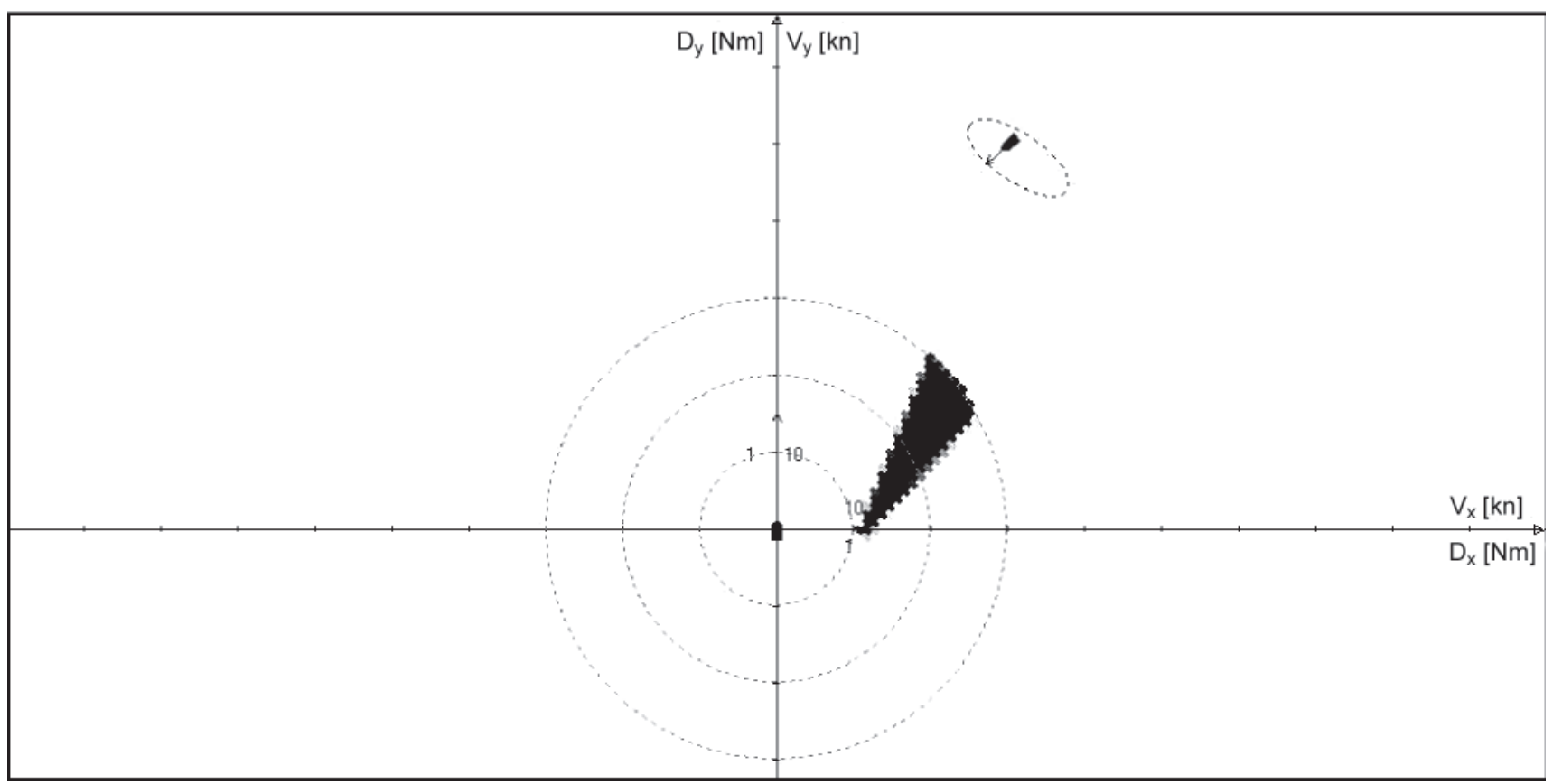

Fig. 4. Direct Collision Threat Parameters Area

Whenever the arrow indicating the end of the own speed vector appears on the dark grey or black background - a collision avoidance manoeuvre should be performed. The closest white point on the display represents a safe combination of the own speed and course. For the situation in Fig. 4 the tip of the own speed vector is on the white background (outside the forbidden sector associated with the target), hence the current combination of course and speed is safe.

\section{AN EXEMPLARY SCENARIO}

In this section it is shown, how visualizing collision risk affects navigational decision. An example, randomly generated scenario, involving 20 targets is analysed here. The initial situation is given in Tab. 1 and Fig. 5.

According to Tab. 1 and Fig. 5, the own ship is approaching a number of target ships, some of them colliding with the

Tab. 1. The positions, courses and speeds of the own ship and the target ships in the exemplary scenario

\begin{tabular}{|c|c|c|c|c|c|c|}
\hline & \multirow{2}{*}{$\begin{array}{c}\text { Speed } \\
{[\text { knots }]}\end{array}$} & \multirow{2}{*}{$\begin{array}{c}\text { Course } \\
\text { [degrees] }\end{array}$} & \multicolumn{2}{|c|}{$\begin{array}{l}\text { Position coordinates at the start } \\
\text { time }\end{array}$} & \multicolumn{2}{|c|}{$\begin{array}{l}\text { Coordinates of the } \\
\text { destination point }\end{array}$} \\
\hline & & & $\mathrm{x}$ [n.m.] & $\mathrm{y}$ [n.m.] & $\mathrm{x}$ [n.m.] & $\mathrm{y}$ [n.m.] \\
\hline Own ship & 15 & 90 & 0 & 5 & 18 & 5 \\
\hline Target 1 & 19.3 & 270 & 15.6 & 7.3 & & \\
\hline Target 2 & 16.3 & 223 & 11.1 & 12.0 & & \\
\hline Target 3 & 9.2 & 334 & 9.8 & 4.4 & & \\
\hline Target 4 & 14.4 & 233 & 18.9 & 5.9 & & \\
\hline Target 5 & 6.8 & 174 & 10.9 & 2.5 & & \\
\hline Target 6 & 12.4 & 167 & 9.4 & 6.9 & & \\
\hline Target 7 & 13.8 & 5 & 5.7 & 6.9 & & \\
\hline Target 8 & 14.8 & 265 & 6.6 & 2.8 & & \\
\hline Target 9 & 9.0 & 306 & 13.3 & 8.6 & & \\
\hline Target 10 & 9.1 & 349 & 15.0 & 9.4 & & \\
\hline Target 11 & 13.6 & 223 & 5.4 & 8.3 & & \\
\hline Target 12 & 6.9 & 49 & 6.4 & 1.7 & & \\
\hline Target 13 & 10.0 & 322 & 8.4 & 4.4 & & \\
\hline Target 14 & 15.3 & 2 & 6.9 & 9.8 & & \\
\hline Target 15 & 15.4 & 3 & 3.0 & 1.0 & & \\
\hline Target 16 & 18.8 & 21 & 19.9 & 6.6 & & \\
\hline Target 17 & 19.0 & 146 & 15.6 & 0.5 & & \\
\hline Target 18 & 15.9 & 352 & 4.0 & 1.6 & & \\
\hline Target 19 & 15.6 & 66 & 10.8 & 8.2 & & \\
\hline Target 20 & 7.4 & 280 & 6.6 & 5.8 & & \\
\hline
\end{tabular}




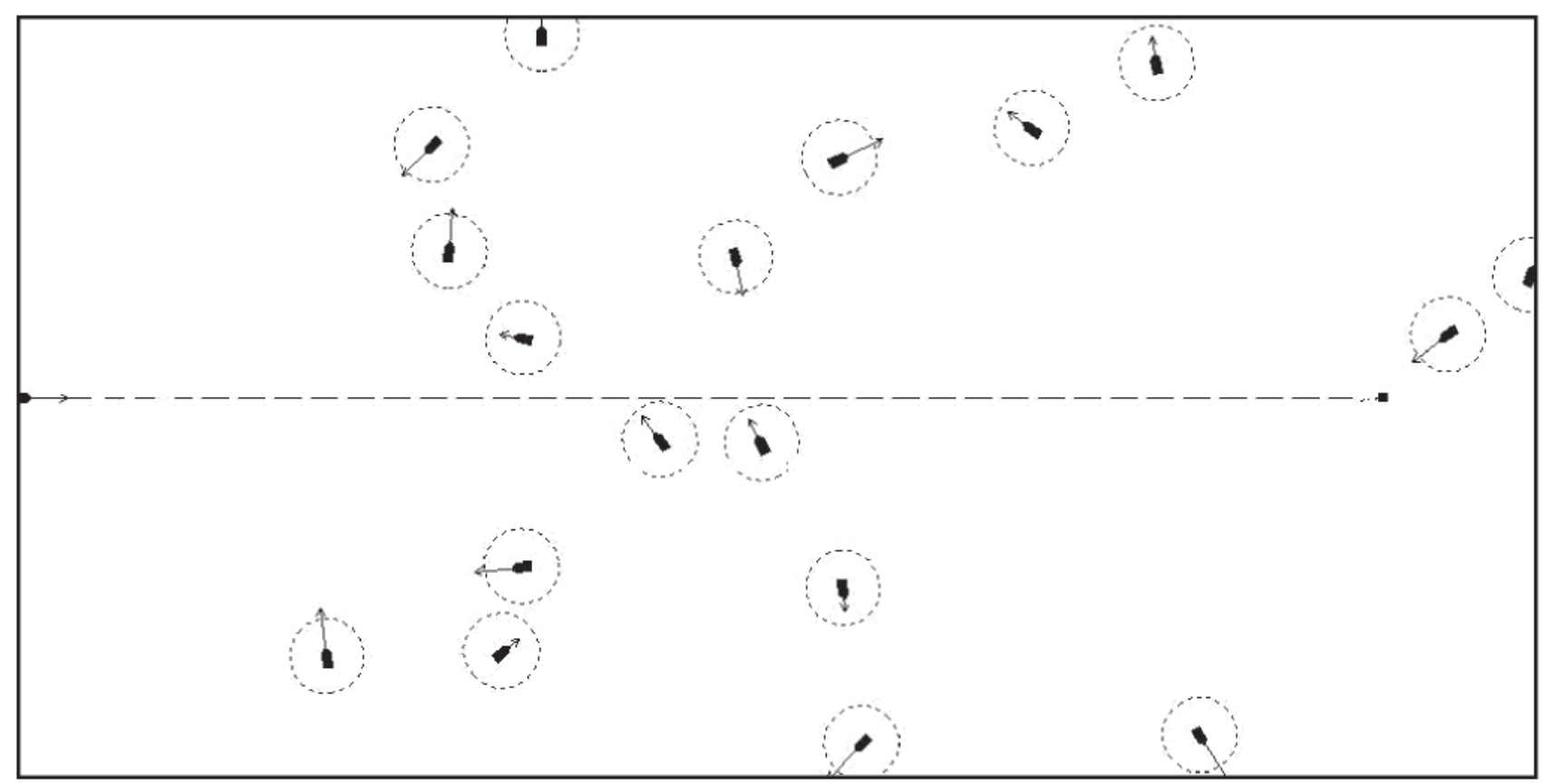

Fig. 5. Position and courses of the own ship and target ships in the exemplary scenario

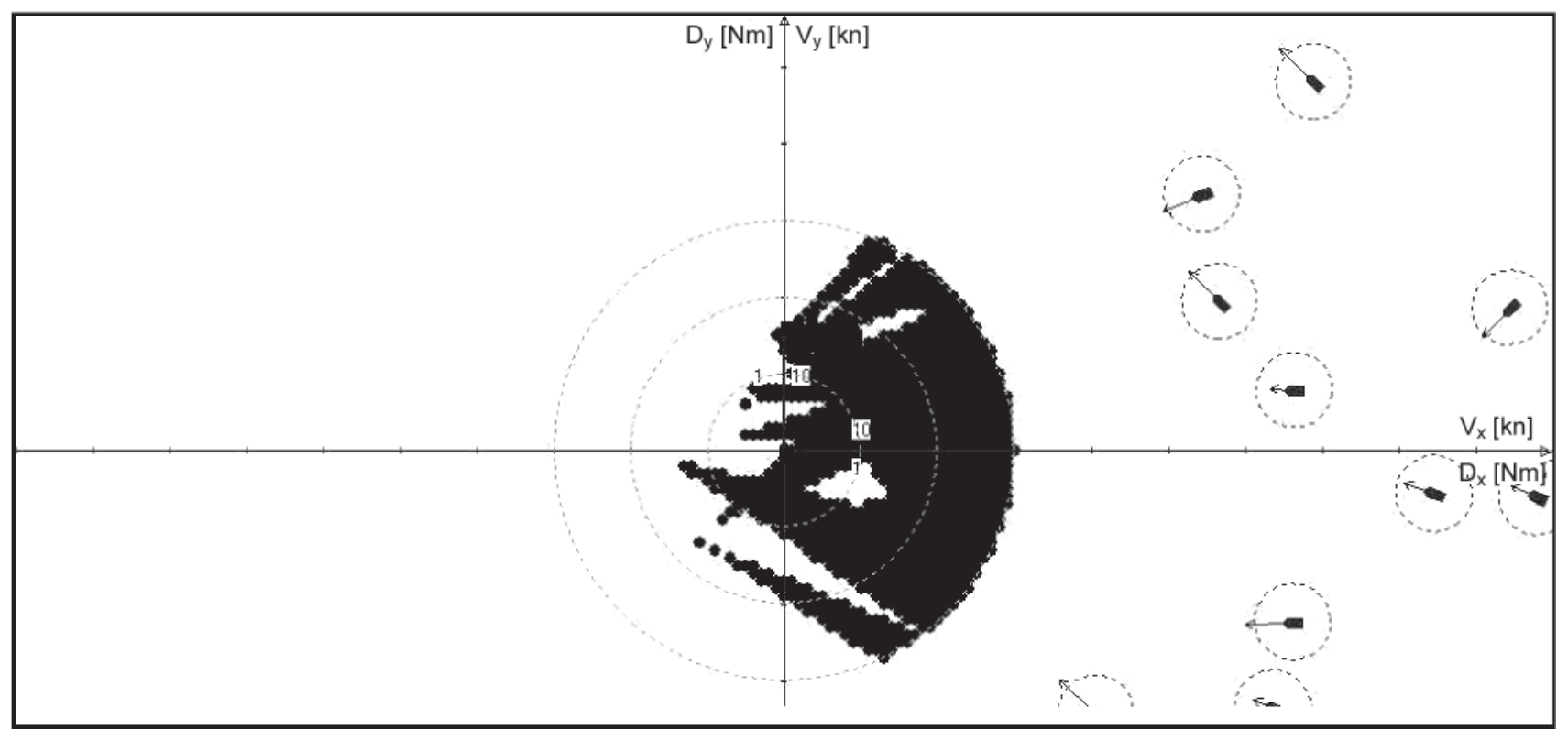

Fig. 6. Forbidden sectors of own course and speed for the exemplary scenario according to CTPA

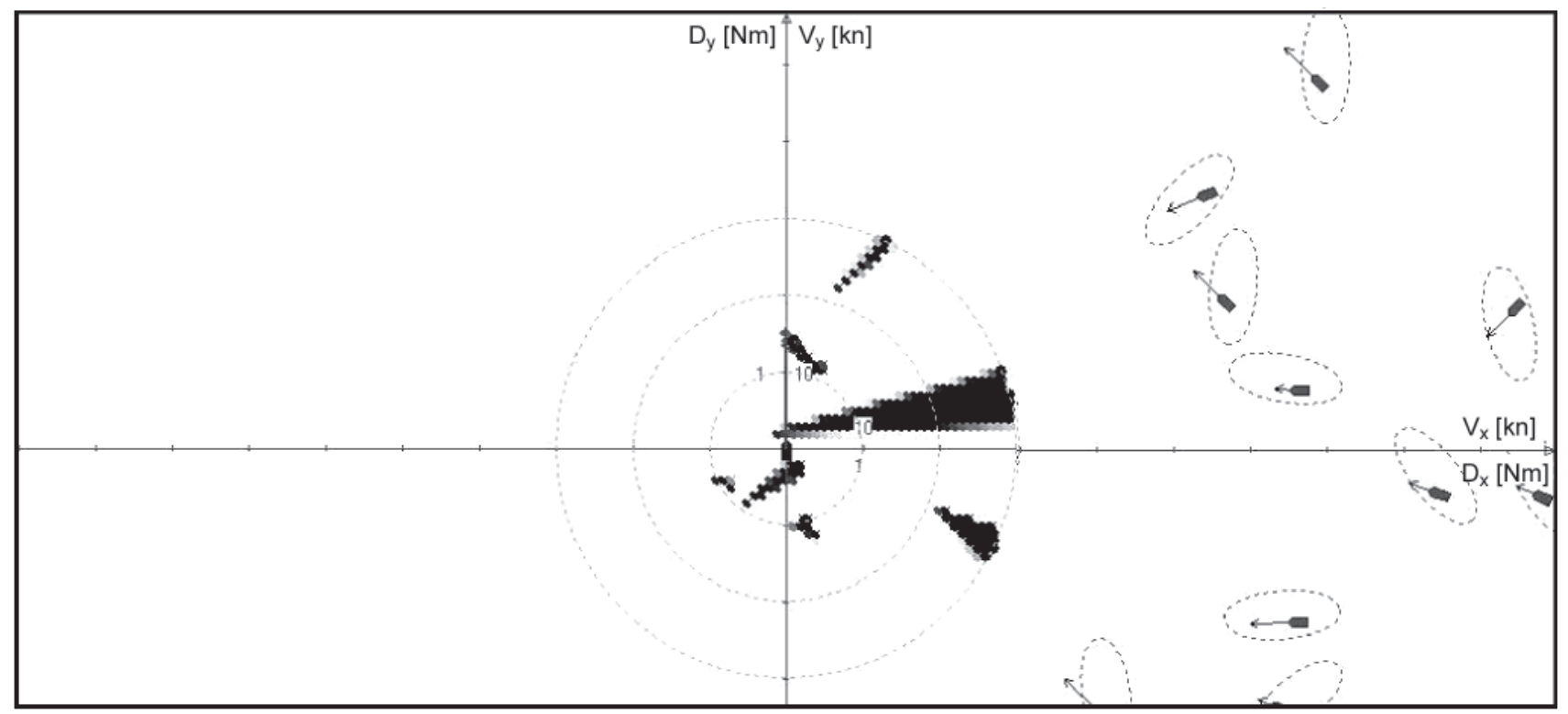

Fig. 7. Forbidden sectors of own course and speed for the exemplary scenario according to DCTPA 


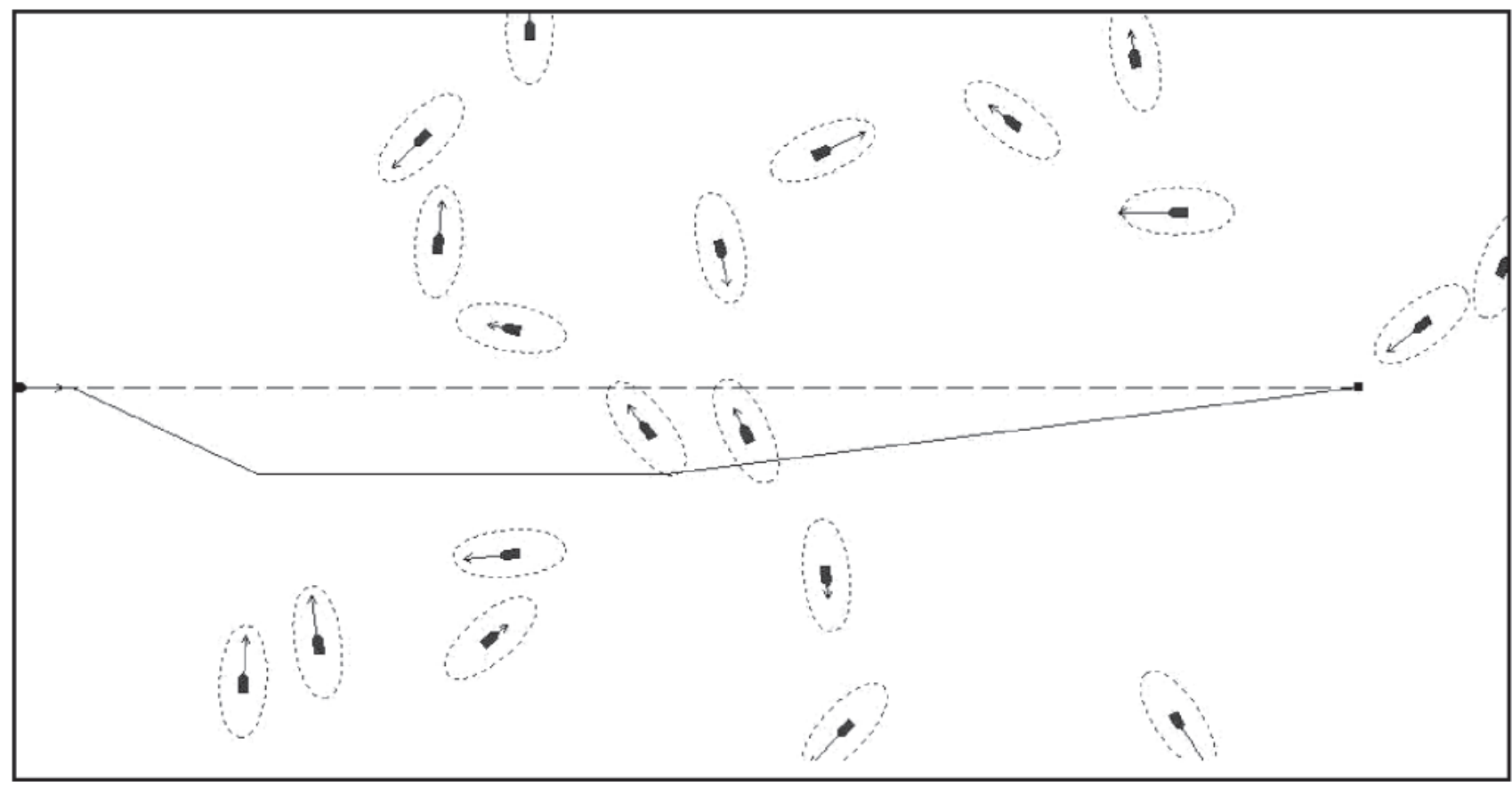

Fig. 8. A safe trajectory of the own ship resulting from a manoeuvre to starboard

own course. The forbidden sectors of own course and speed (Collision Threat Parameters Area) for the safe distance of 0.5 nautical mile look as shown in Fig. 6. Due to the large number of targets it is impossible to choose a single course alteration manoeuvre to starboard (recommended by COLREGS) that avoids collisions with all of the targets.

However, applying the proposed visualization tool enables the navigator to assess the situation better than that. According to the proposed method, the Direct Collision Threat Parameters Area for the initial situation looks as depicted In Fig. 7. The Coldwell domain is used here for target ships.

From the collision risk visualized in Fig. 7, the navigator may easily conclude, that although the current course and speed are not safe (the tip of the own speed vector is on the forbidden area), it is possible to perform a course alteration manoeuvre to starboard, which avoids collision with the directly threatening target. As a result, a trajectory containing the manoeuvre to starboard might be planned, as shown in Fig. 8.

\section{SUMMARY AND CONCLUSIONS}

Visualizing collision risk is especially important in multi-ship encounter situations, when the own course and speed collides with more than one target. Unfortunately, in such situations it is not always possible to avoid collision by performing a single, lawful collision avoidance manoeuvre. Therefore the targets have to be ranked according to the risk they constitute. This risk depends not only on the minimum distance between the ships (or the domain violation) but also on the time remaining to the point of the closest approach. Particularly threatening are situations when domain violations are accompanied by short times remaining to the encounters. In such situations the proposed solution enables the navigator to point out the most dangerous targets and avoid them in the first place. Once these targets have been safely passed, the navigator may focus on the targets constituting lesser risk. The proposed solution is fast enough to be applied in the real-time decisionsupport system, where fast processing of the data concerning all targets is a necessity.

\section{BIBLIOGRAPHY}

1. Lenart A.S.: Collision threat parameters for a new radar display and plot technique. The Journal of Navigation, 36, 1982
2. Lisowski J.: Determining the Optimal Ship Trajectory in Collision Situation. Proceedings of the IX International Scientific and Technical Conference on Marine Traffic Engineering, AM, Szczecin, 2001

3. Pietrzykowski Z., Gucma L.: Theoretical Basis of the Probabilistic - Fuzzy Method for Assessment of Dangerous Situation of a Ship Manoeuvring in a Restricted Area (in Polish). Annual of Navigation 3, Academy of Sciences, Polish Navigation Forum, Gdynia, 2001

4. Szłapczyński R.: A unified measure of collision risk derived from the concept of a ship domain. Journal of Navigation, 59, issue 3, 2006

5. Szłapczyński R.: Fuzzy Collision Threat Parameters Area (FCTPA) - a new display proposal. Proceedings of the 7th International Symposium of Navigation TransNav'2007. AM, Gdynia, 2007

6. Śmierzchalski R.: Decision support in collision situation at sea (in Polish). Proceedings of the $4^{\text {th }}$ International Symposium Technological Progress of Military Equipment „Inter-Arms”, Gdynia, 1996

7. Śmierzchalski R.: The Decision Support System to Design the Safe Manoeuvre Avoiding Collision at Sea. Proceedings of the $14^{\text {th }}$ International Conference Information Systems Analysis and Synthesis, Orlando, 1996

8. Śmierzchalski R.: Practical methods to make decision of safe manoeuvre and trajectory avoiding collision at sea. ELMAR 2000, Zadar, 2000

9. Sperry Marine ARPA - CAS II - technical documentation.

\section{CONTACT WITH AUTHORS}

Rafał Szłapczyński, Ph. D. Faculty of Mechanical Engineering Gdansk University of Technology Narutowicza 11/12

80-952 Gdansk, POLAND e-mail :rafal@pg.gda.pl

Roman Śmierzchalski, Assoc. Prof. Faculty of Marine Engineering, Gdynia Maritime University Morska 83 81-225 Gdynia, POLAND e-mail: roms@am.gdynia.pl 